(c) American Dairy Science Association, 2006.

\title{
Forecasting Fluid Milk and Cheese Demands for the Next Decade
}

\author{
T. M. Schmit ${ }^{1}$ and H. M. Kaiser \\ *Department of Applied Economics and Management, Cornell University, Ithaca, NY 14853
}

\begin{abstract}
Predictions of future market demands and farm prices for dairy products are important determinants in developing marketing strategies and farm-production planning decisions. The objective of this report was to use current aggregate forecast data, combined with existing econometric models of demand and supply, to forecast retail demands for fluid milk and cheese and the supply and price of farm milk over the next decade. In doing so, we can investigate whether projections of population and consumer food-spending patterns will extend or alter current consumption trends and examine the implications of future generic advertising strategies for dairy products. To conduct the forecast simulations and appropriately allocate the farm milk supply to various uses, we used a partial equilibrium model of the US domestic dairy sector that segmented the industry into retail, wholesale, and farm markets. Model simulation results indicated that declines in retail per capita demand would persist but at a reduced rate from years past and that retail per capita demand for cheese would continue to grow and strengthen over the next decade. These predictions rely on expected changes in the size of populations of various ages, races, and ethnicities and on existing patterns of spending on food at home and away from home. The combined effect of these forecasted changes in demand levels was reflected in annualized growth in the total farm-milk supply that was similar to growth realized during the past few years. Although we expect nominal farm milk prices to increase over the next decade, we expect real prices (relative to assumed growth in feed costs) to remain relatively stable and show no increase until the end of the forecast period. Supplemental industry model simulations also suggested that net losses in producer revenues would result if only nominal levels of generic advertising spending were maintained in forthcoming years. In fact, if real generic advertising expenditures are increased relative to 2005 levels, returns to the investment in generic advertising can be improved.
\end{abstract}

Received June 5, 2006.

Accepted July 18, 2006.

${ }^{1}$ Corresponding author: tms1@cornell.edu
Specifically, each additional real dollar invested in generic advertising for fluid milk and cheese products over the forecast period would result in an additional $\$ 5.61$ in producer revenues.

Key words: fluid milk, cheese, demand, supply

\section{INTRODUCTION}

Trends in per capita demands for fluid milk and cheese in the United States have traced different paths over time: per capita cheese demand has been increasing whereas per capita fluid milk demand has fallen (Figure 1). Dairy producers in the United States have questions about both trends-will the downward trend in fluid milk demand persist into the future, and is the favorable trend for cheese approaching its peak? In addition, forecasts of demands and other market factors are useful to product marketers and farmers in marketing and production planning.

Studies have shown that recent changes in per capita demand for dairy products are mainly a result of changes in population demographics and food-spending patterns, not of direct changes in economic variables such as real price or income. For example, for 1995 through 2004, Kaiser (2005) estimated that the primary factor contributing to the reduction in per capita fluid milk demand was a decrease in the portion of the population that is $5 \mathrm{yr}$ of age and younger, followed (distantly) by increases in real retail prices. The same study found that the most important contributors to growth in per capita cheese demand were a growing Hispanic population and increases in per capita spending on food away from home, followed by the lesser effects of rising real disposable incomes.

The objective of this report was to use current USDA (2006) and US Census Bureau (2004) market projection data, combined with existing econometric models of demand and supply, to forecast the retail demands for fluid milk and cheese and the supply and price of farm milk over the next decade. By doing so, we investigated whether projections of population and consumer foodspending habits would extend or alter current consumption trends. In addition, we examined the market impacts of future generic advertising strategies for dairy products. 


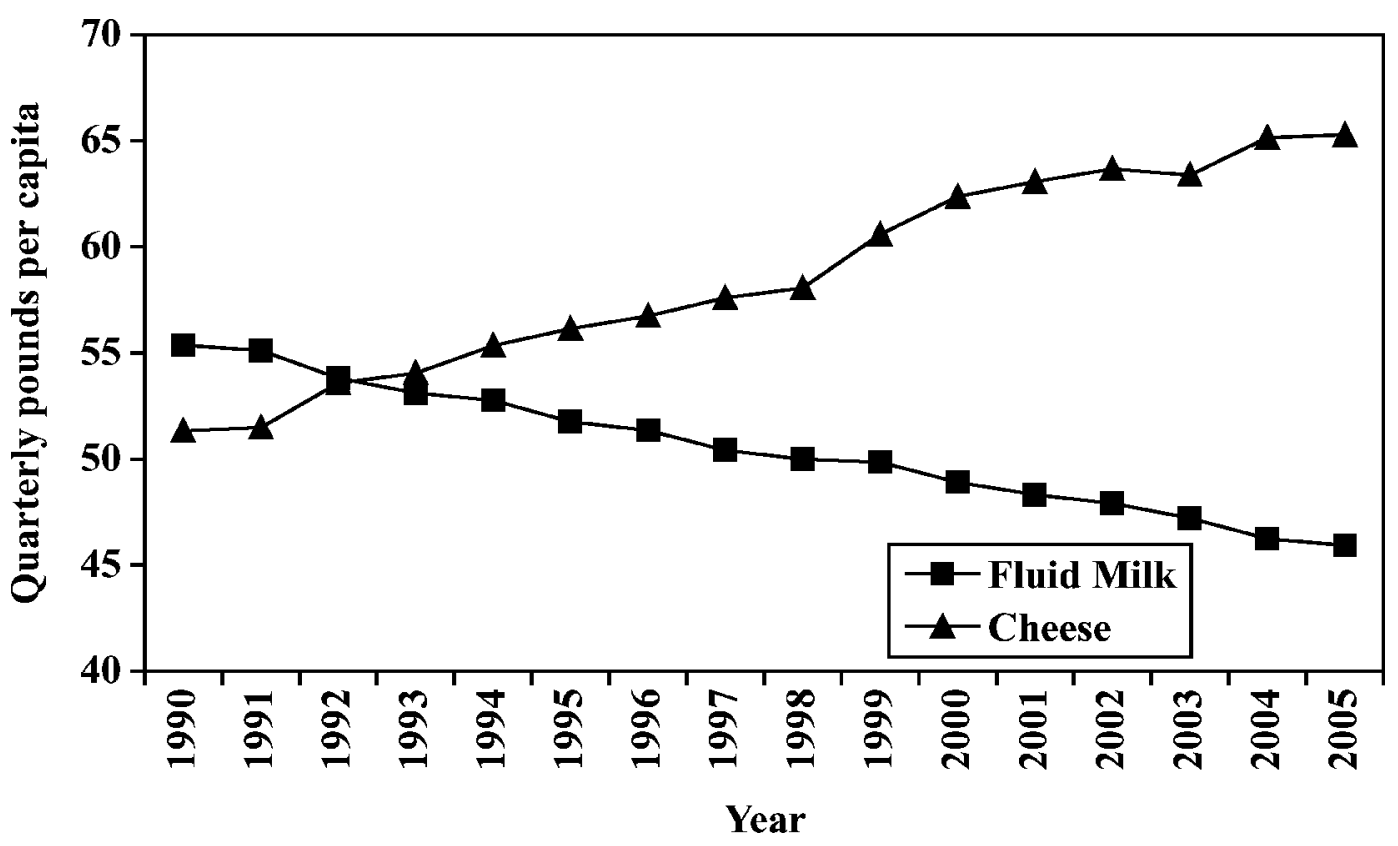

Figure 1. Historical retail fluid milk and cheese demand per capita, 1990-2005.

\section{MATERIALS AND METHODS}

To conduct the forecast simulations and appropriately allocate the milk supply to various uses, we used a partial equilibrium model of the US domestic dairy sector. The industry was segmented into retail, wholesale, and farm markets in the full model, in which the wholesale markets provide the link between farm supply and retail quantities. Farm, wholesale, and retail supply-side economic relationships were taken from Schmit and Kaiser (2002) and retail time-varying demand models for fluid milk and cheese were taken from Schmit and Kaiser (2004) to conduct the forecast simulations. In these 2 studies, the estimated parameters in all equations were computed using national data from 1975 through 2001. We updated the data from these 2 studies with more recent USDA and census information and added data for 2002 through 2005. This allowed us to evaluate both the adjusted withinsample period (1997-2001) and the ex post forecasts (2002-2005) generated by the model and thereby determine the model's suitability for forecasting over the next decade (2006-2015).

\section{Model Simulation Structure}

To evaluate the future demand and supply effects of projected market variables, we simulated time-varying retail demand models for fluid milk and cheese with estimated supply relationships at the retail, wholesale, and farm levels. To set the stage for the forecast simula- tion, we will briefly highlight the structure of the industry model, including the supply-side market relations, and specification of the time-varying retail demand models for fluid milk and cheese. For detailed econometric estimates of the demand and supply equations, see Schmit and Kaiser (2002, 2004).

Supply-Side Modeling. The industry simulation model was adapted from Liu et al. (1990) and represents a partial equilibrium model of the US domestic dairy sector (without trade) that divides the industry into retail, wholesale, and farm markets. The general structure of the model is one that begins in the farm market, where Grade A (fluid eligible) milk is produced by farmers and sold to wholesalers. The wholesale market is disaggregated into 3 submarkets: fluid (beverage) milk, cheese, and other manufactured. Although the fluid milk and cheese sectors were explicitly modeled, other manufactured dairy products (e.g., butter and frozen products) were assumed to be exogenous to the industry model and were incorporated only through their inclusion in equilibrium closing conditions. Wholesalers, in turn, process the milk into these products and sell them to retailers, who then sell the products to consumers. All quantities (except fluid milk) are expressed on a milk fat-equivalent basis. Fluid milk is expressed in product form (pounds).

The model incorporated existing federal regulatory programs of milk marketing orders and the dairy price support program (DPSP). Given that the model is national in scope, we assumed that there was one federal 
milk marketing order regulating all milk and incorporated the order by restricting the prices that wholesalers pay for raw milk to minimum class prices. As such, fluid milk wholesalers pay the higher Class I price whereas cheese wholesalers pay the Class III price. Farm milk prices were then computed based on the distribution of farm milk to alternative product uses. The DPSP was incorporated by requiring that cheese prices be equal to or greater than the government purchase price for cheese and by assuming that the government purchases all excess storable manufactured dairy products at announced purchase prices. Given that the simulation model was based on estimated economic relations using data through 2001, it did not include a component for USDA's current Milk Income Loss Contract program (MILC). This program compensates eligible producers when domestic milk prices fall below a specified level each fiscal year up to a maximum payment quantity of 2.4 million pounds. Payments from the program increased in 2006 relative to the previous $2 \mathrm{yr}$, given reductions in farm milk prices. However, analyzing predicted prices from the simulation results indicated an increasing trend in nominal class prices for the forecast period with only 1 yr (2006) showing predicted annual prices that would trigger MILC program payments. As such, the exclusion of this policy component should have little effect on the results reported here.

Reflecting retail supply operations and linkages in the market chain, the retail supply equations for fluid milk and cheese were expressed as a function of: 1) retail price, 2) wholesale price (a variable cost to retailers), 3) a price index for fuel and energy (another variable cost), 4) a time trend as a proxy for technical change in retailing, 5) seasonal dummy variables, and 6) lagged retail supply to represent capacity constraints. The wholesale supply equations were similarly modeled as a function of 1) wholesale price, 2) the corresponding class price (a variable cost to wholesalers); the Class I milk price is defined as the Class III milk price plus a fixed fluid milk price differential, 3) a price index for fuel and energy (another variable cost), 4) a time trend as a proxy for technological change in dairy product processing, 5) seasonal dummy variables, and 6) lagged wholesale supply to represent capacity constraints.

Specification of the wholesale cheese market is complicated by the fact that impacts of the DPSP occur here. We must account for total inventory decisions because the Commodity Credit Corporation can provide an alternative source of demand by purchasing excess storable products at announced government purchase prices. In particular, the DPSP constrains the wholesale cheese price to an amount that is equal to or greater than the announced government purchase price. When the industry price for cheese is less than the announced government price, the equilibrium condition must be augmented with government purchases of cheese and the price is fixed at the announced government level. In addition, total wholesale cheese supplies also reflect changes in stored inventories and quantities of cheese sold by specialty plants to the government. Specialtyplant sales and changes in inventories represented a small portion of total production and were assumed to be exogenous in the model.

Finally, the farm-level milk supply was specified as a function of 1) the all-milk price, 2) the ration price, 3 ) the slaughter-cow price, 4) a time trend as a proxy for technological change in dairy production, 5) seasonal dummy variables, 6) intercept shifters for periods in which the milk diversion program and the dairy termination program were in effect, and 7) lagged farm supply to account for rigidities in production adjustments. The all-milk price is endogenous and was defined as a weighted average of the class prices for milk. To close the model in equilibrium, the farm milk supply must equal the sum of wholesale supplies of fluid milk, cheese, and other manufactured products and onfarm use.

Demand-Side Modeling. Given the model specification, the wholesale demand functions did not need to be estimated because the equilibrium conditions constrained the wholesale demands to equal the equilibrium retail quantities. These conditions also implied a fixed-proportions technology between the retail and wholesale market levels. The retail demands did, however, need to be specified and were constrained to equal the respective retail supply quantities in equilibrium.

The retail demand models for fluid milk and cheese, taken from Schmit and Kaiser (2004), explicitly accounted for the effect of economic, demographic, and advertising factors on per capita demand (i.e., direct effects on demand). In addition, the effect of changes in generic advertising response over time due to changes in specific economic, demographic, and consumer food-spending characteristics were empirically estimated in the model (i.e., indirect effects on demand). Because market characteristics change over time, it is reasonable to assume that the overall effectiveness of the advertising program may change as well. In addition, relating the variation in advertising response to specific market factors provides critical information to product marketers for adjusting future campaigns to enhance demand response for their products (Schmit and Kaiser, 2004).

Following Schmit and Kaiser (2004), the direct effects of variation in per capita fluid milk demand included: 1) retail product prices (fluid milk and competing nonalcoholic beverages), 2) real per capita disposable income, 
3) the percentage of the US population under $5 \mathrm{yr}$ of age, 4) an intercept shifter for the periods after bST was introduced, 5) seasonal dummy variables, 6) national branded and generic fluid milk advertising expenditures, and 7) a residual time trend variable. Indirect changes in per capita fluid milk demand, as modeled through changes in the marginal level of response to generic advertising, were similarly defined as a function of 1) retail prices (fluid milk and competing products), 2) real per capita disposable income, 3) the percentage of the US population under $5 \mathrm{yr}$ of age, and 4) the percentage of the US population identified as African American.

Similarly, Schmit and Kaiser (2004) defined the direct effects of variation in per capita cheese demand as: 1) retail product prices (cheese and meat products), 2) real per capita disposable income, 3) the percentage of the US population identified as Asian or Hispanic, 4) real per capita expenditures on food eaten away from home, 5) seasonal dummy variables, and 6) national branded and generic cheese advertising expenditures. Indirect changes in per capita cheese demand, as modeled through changes in the marginal level of response to generic advertising, were similarly defined as a function of 1) retail prices (cheese and meat products), 2) real per capita disposable income, 3) real per capita expenditures on food eaten away from home, 4) the percentage of the US population between 20 and 44 yr of age, and 5) the percentage of the US population identified as Asian or Hispanic.

Given the nonlinear specification of the time-varying demand models, the regression results are more clearly interpreted when evaluated in terms of elasticities. In general, demand elasticities represent the relative responsiveness or sensitivity of demand to changes in various explanatory variables. Specifically, the demand elasticities represent the percentage change in demand as a result of $1 \%$ change in the variable of interest when all other variables are held constant. Given that elasticities are unitless in measure, the relative sizes of the elasticities can be readily compared across explanatory variables. To better understand the forthcoming forecast results, we follow with a brief review of selected elasticity results computed at the sample means by Schmit and Kaiser (2004) that are shown in Table 1.

Negative price elasticities conform to economic theory in that increases in real prices reduce consumer demand. Income elasticities are positive and inelastic for both products, indicating that these products are normal goods; that is, increases in real income increase demand. The positive sign on per capita expenditures for food away from home in the cheese equation also is consistent with the expectation that per capita cheese consumption is greater away from home (e.g., in restaurants). The positive and relatively large elasticity for the young-age cohort for fluid milk reflects the greater nutritional demands of young children, whereas the effect of the middle-aged cohort for cheese consumption was small and not statistically different from zero. Race effects were as expected-African Americans consumed less fluid milk and Asians and Hispanics consumed more cheese.

Branded advertising expenditures did not significantly contribute to total market demand changes for either product. Although all advertising seeks to increase sales, brand-advertising efforts are heavily concentrated on gaining market share from competitors. In contrast, the demand effects of generic advertising for fluid milk and cheese, although smaller than those realized for the demographic variables, were statistically significant in both models.

As dictated by economic theory, increases (decreases) in supply are expected from increases (decreases) in output prices or decreases (increases) in input prices, all else held constant. Given that output (revenue) prices for one market (say, the wholesale supply market) also represent the input (cost) prices for the next upward market (say, the retail supply market) in the industry system, it is the relative movements of these prices, along with shifting supply and demand schedules and equilibrium closing conditions, that dictate the annual equilibrium price and quantity results. For example, an increase in food spending away from home is expected to shift the demand up for cheese at the retail level. This, in turn, will increase the demand for cheese by retailers, increasing the wholesale price of cheese. Cheese wholesalers subsequently increase their demand for milk increasing the derived demand for milk as cheese and, thus, affecting the Class III price and the all-milk price received by farmers. Milk producers subsequently adjust production in the face of higher relative prices. Of course, no single "shock" to the system happens in isolation; rather, numerous impacts are occurring simultaneously across products and market levels. As such, a simulation model that accounts for all important factors simultaneously is needed. Given the combination of all of these factors, supplies and demand will adjust with changes in relative prices to reach a new equilibrium at each point in time.

\section{Forecast Data}

All exogenous variables included in the industry model are projected to the year 2015 using 1 of 3 sources: 1) USDA agricultural projections (2006), 2) US Census Bureau population projections (2004), or 3) author assumptions (Table 2). We obtained US Census popula- 
Table 1. Selected demand elasticities evaluated at sample means (SE in parentheses $)^{1}$

\begin{tabular}{lcc}
\hline Variable & Fluid milk & Cheese \\
\hline Price & -0.039 & $-0.347^{*}$ \\
& $(0.039)$ & $(0.091)$ \\
Income & $0.418^{*}$ & $0.662^{*}$ \\
& $(0.132)$ & $(0.107)$ \\
Per capita expenditures for food away from home & $\mathrm{NA}$ & $0.428^{*}$ \\
& & $0.086)$ \\
Proportion of population aged 5 or younger & $0.831^{*}$ & $\mathrm{NA}$ \\
Proportion of population aged 20 to 44 & $(0.113)$ & 0.078 \\
& $\mathrm{NA}$ & $(0.135)$ \\
Proportion of population that is African American & $-0.601 \dagger$ & $\mathrm{NA}$ \\
Proportion of population that is Asian or Hispanic & $(0.369)$ & $0.269^{*}$ \\
Branded advertising & $\mathrm{NA}$ & $(0.057)$ \\
Generic advertising & -0.004 & -0.001 \\
& $(0.007)$ & $(0.017)$ \\
& $0.040^{*}$ & $0.013 \dagger$ \\
\hline
\end{tabular}

${ }^{1}$ Schmit and Kaiser (2004).

$\dagger P<0.10 ; * P<0.05$. tion projections for 2000 through 2050 . We include the period from 2006 through 2015 in this analysis and calibrate projected annual changes to existing actual data starting in 2005.

All retail consumer price indexes were expected to show steady increases over the forecast period, with average annual percentage changes over the forecast period of 2.9, 2.3, and $0.7 \%$ for all products, nonalcoholic beverages, and retail meat products, respectively. The resident population was expected to increase from 297 million in 2005 to more than 322 million by 2015 , the equivalent of a $0.9 \%$ average annual rate of growth.

Minority populations also were expected to continue to increase in both size and proportion during the next decade. Specifically, strong growth in the Asian population was anticipated-an average annualized growth rate of nearly $1.9 \%$ and a population proportion of nearly $5.5 \%$ by 2015 . The Hispanic population was ex-

Table 2. Exogenous variable sources and assumptions for baseline simulation

\begin{tabular}{|c|c|}
\hline Source/exogenous variable & Assumption \\
\hline \multicolumn{2}{|l|}{ USDA (2006): } \\
\hline Consumer price index (CPI), US all & Projected \\
\hline CPI, US nonalcoholic beverages & Projected \\
\hline CPI, US meat & Projected \\
\hline Disposable personal income & Projected \\
\hline Energy index & Tied to projected crude oil prices \\
\hline Dairy ration cost & Tied to projected corn prices \\
\hline Dairy cow sales price (nonslaughter) & Tied to projected milk prices \\
\hline On-farm milk use & Projected \\
\hline \multicolumn{2}{|l|}{ US Census Bureau (2004): } \\
\hline Resident population & Projected \\
\hline Percent population African American & Scaled to actual 2005 level, trend on projection \\
\hline Percent population Asian & Scaled to actual 2005 level, trend on projection \\
\hline Percent population Hispanic & Scaled to actual 2005 level, trend on projection \\
\hline Percent population aged 5 or younger & Scaled to actual 2005 level, trend on projection \\
\hline Percent population aged $20-44$ & Scaled to actual 2005 level, trend on projection \\
\hline \multicolumn{2}{|l|}{ Author assumption: } \\
\hline Butter and frozen supply and demand & Per capita consumption fixed at 2005 level \\
\hline Government cheese purchase price & Fixed at 2005 announced price \\
\hline Government cheese and butter inventories & Fixed at 2005 level \\
\hline Class I price differential $=\$ 2.5 / \mathrm{cwt}$ & Fixed at $2003-2005$ average differential \\
\hline Real per capita expenditures $\mathrm{FAFH}^{1}$ & Fixed growth, $1.5 \%$ per year, $2003-2005$ average \\
\hline National branded advertising expenditures ${ }^{2}$ & Fixed at 2005 real per capita expenditure level \\
\hline National generic advertising expenditures ${ }^{2}$ & Fixed at 2005 real per capita expenditure level \\
\hline
\end{tabular}

${ }^{1} \mathrm{FAFH}=$ Food eaten away from home.

${ }^{2}$ Advertising expenditures for fluid milk and cheese products. 
pected to have similar consistent growth-an annualized growth rate of nearly $1.8 \%$ over the sample period and a population proportion of nearly $16 \%$ by 2015 . Finally, the African American population was expected to continue to grow in proportion to the total population but at a slower annualized rate of only $0.3 \%$ per year.

The current downward trend in the proportion of the population that is middle-aged (age 20 through 44) was projected to continue for the next decade; however, the declines were expected to be modest, with average annual decreases of only $0.6 \%$. A strong demand cohort for fluid milk is children age 5 and younger, a group with a critical need for calcium and therefore for fluid milk. Recent modest gains in the portion of the population within this cohort were expected to fade at the beginning of the forecast period and thereafter show variable modest increases and decreases. Overall, relative to 2005 , very little if any change in this portion of the population is expected in the next decade. Conversely, growth in real income was expected to be strong over the next decade with an annual average growth rate exceeding $2.5 \%$.

Several supply-side costs and prices were required for the industry simulation. Dairy ration costs have varied in recent years due to fluctuating feed prices. We assumed that future ration costs would vary in proportion to expected changes in a dominant feed cost component, corn. On that basis, we anticipated relatively large increases in ration costs early on, followed by relatively stable costs during the final 7 forecast years. In total, average annualized growth in ration costs over the simulation period was expected to be around $4.4 \%$.

The energy cost index was assumed to move proportionally with expected crude oil prices. The past $2 \mathrm{yr}$ have shown significant increases in oil costs and those higher levels are expected to stabilize during the first half of the simulation period and then increase steadily beginning in 2010 . Relative to 2005 , this implies a modest $1.4 \%$ annualized growth rate.

Assuming that the sales value of dairy cows (nonslaughter) is positively related to the animals' earning potential and hence the milk price, we indexed cow prices to expected farm-level milk prices. In real terms (i.e., relative to changes in expected ration costs), this implied a reduction in value at the beginning of the forecast period and an average annualized negative growth rate of nearly $-3 \%$ per year.

Total butter and frozen-product supply and demand were assumed to be exogenous to the system with total future annual disappearance levels computed by assuming fixed per capita consumption at 2005 levels. We then adjusted the total disappearance levels based on forecasted changes in the US population. Butter and frozen-product demands represented approximately $25 \%$ of total dairy demand and have shown relatively flat consumption patterns, increasing only $1.1 \%$ in total over the past 5 yr. Similarly, butter and cheese inventories and the government purchase price for cheese were assumed to be fixed at 2005 levels. Average annual cheese inventories have been relatively constant since 2000 (i.e., around 6.58 billion pounds per quarter) and the 2005 butter inventory level ( 2.70 billion pounds per quarter) is quite close to the 5-yr average since 2000 (3.07 billion pounds). The announced government purchase price for cheese has not changed since 1998.

The Class I fluid milk price differential was assumed to be fixed at $\$ 2.51$ per hundredweight (cwt), which was the annual average between 2003 and 2005. Over this period the average annual differential varied widely from $\$ 1.96$ to $\$ 3.04$. The $\$ 2.51$ assumed rate was also within the narrower range in earlier years; i.e., from $\$ 2.41$ to $\$ 2.93$ from 2000 to 2003 . Supplemental sensitivity analysis on the differential level showed that the general results presented here are robust to changes in the differential. Finally, real per capita expenditures on food eaten away from home, an important demand determinant for total cheese disappearance, have shown steady growth in recent years. Consequently, we assumed a fixed annual growth rate of $1.5 \%$, the average growth rate between 2003 and 2005, and conducted additional sensitivity analysis around this rate as described below.

In our baseline forecast, we assumed that real generic fluid milk and cheese advertising expenditures per capita were constant throughout the forecast period and we set them equal to spending levels in 2005. This was equivalent to $\$ 8.29$ per 100 people per quarter for fluid milk and $\$ 2.37$ per 100 people per quarter for cheese in 2005 dollars, or an average of $\$ 132.34$ million per year. Note that fluid milk advertising includes generic advertising spending from check-off contributions by both farmers and fluid milk processors. Also note that we allocated the generic advertising spending allocations to fluid milk and cheese products individually, which is consistent with the estimated demand models. This included allocating expenditures for the recent Three-a-Day advertising program for fluid milk, cheese, and yogurt combined as $40 \%$ to fluid milk advertising and $40 \%$ to cheese advertising (20\% is assumed to have been allocated to yogurt advertising).

We similarly fixed the per capita branded fluid milk and cheese advertising expenditures at 2005 real average quarterly levels, or $\$ 2.10$ and $\$ 8.92$ per 100 people, respectively. Note that the assumption of fixing real per capita advertising spending still implies increases in annual nominal spending in proportion to increases in unit advertising media costs to maintain the current 
Table 3. Within-sample and ex post forecast statistics for fluid milk and cheese demand and farm milk supply ${ }^{1}$

\begin{tabular}{|c|c|c|c|c|c|c|c|c|c|}
\hline \multirow[b]{2}{*}{ Sample period } & \multicolumn{3}{|c|}{$\begin{array}{l}\text { Fluid milk demand per capita } \\
\text { (pounds per quarter) }\end{array}$} & \multicolumn{3}{|c|}{$\begin{array}{l}\text { Cheese demand per capita } \\
\text { (pounds per quarter) }\end{array}$} & \multicolumn{3}{|c|}{$\begin{array}{c}\text { Farm milk supply } \\
\text { (billion pounds per quarter) }\end{array}$} \\
\hline & Actual & Predicted & $\mathrm{RMSE}^{2}$ & Actual & Predicted & RMSE & Actual & Predicted & RMSE \\
\hline $\begin{array}{l}\text { Within-sample } \\
\text { 1997-2001 }\end{array}$ & $\begin{array}{l}49.50 \\
(0.86)\end{array}$ & & $0.83 \%$ & $\begin{array}{l}60.34 \\
(2.47)\end{array}$ & $\begin{array}{l}60.31 \\
(1.31)\end{array}$ & $2.65 \%$ & $\begin{array}{l}40.45 \\
(1.25)\end{array}$ & $\begin{array}{l}40.37 \\
(0.60)\end{array}$ & $2.52 \%$ \\
\hline $\begin{array}{l}\text { Ex post } \\
2002-2005\end{array}$ & $\begin{array}{l}46.82 \\
(0.91)\end{array}$ & $\begin{array}{l}46.77 \\
(0.55)\end{array}$ & $0.73 \%$ & $\begin{array}{l}64.32 \\
(0.92)\end{array}$ & $\begin{array}{l}63.95 \\
(0.57)\end{array}$ & $1.62 \%$ & $\begin{array}{l}43.02 \\
(0.82)\end{array}$ & $\begin{array}{l}42.39 \\
(0.58)\end{array}$ & $1.51 \%$ \\
\hline
\end{tabular}

${ }^{1}$ Actual and predicted estimates represent average annual estimates with standard errors in parentheses. ${ }^{2} \mathrm{RMSE}=$ Percentage root mean square error $=100 \sqrt{\left.\frac{1}{N} \sum_{j=1}^{N}\left(\hat{y}_{j}-y_{j}\right) / y_{j}\right)^{2}}$, where $N$ is the number of observations, $y_{i}$ is the actual data value, and $\hat{y}_{i}$ is the predicted data value.

${ }^{3}$ Note that the within-sample data have been updated since the models were originally estimated.

level of advertising activity. We conducted supplemental simulations in which we assumed changes in generic advertising spending over the forecast period to ascertain market impacts.

Note that the estimated supply and demand econometric models used quarterly time-series data whereas forecasted input data were available on an annual basis only. We therefore calibrated the input data in the demand and supply models to average annual quarterly levels. The forecasted results were similarly interpreted as, for example, average quarterly demand and supply levels each year.

\section{RESULTS AND DISCUSSION}

To ascertain whether the industry model we incorporated with the estimated supply and demand relations was sufficient for forecast purposes, we evaluated the model's within-sample (1997-2001) and ex post (20022005) performance relative to the actual outputs realized over these periods. Prediction statistics for the key supply and demand variables are shown in Table 3. Note that we used more recently revised data for the within-sample prediction than originally used for the model parameter estimation. The prediction statistics were encouraging, with all predictions falling below a $3 \%$ root mean square error (RMSE) and deemed sufficient for future forecasting. The percentage RMSE was calculated as:

$$
R M S E=100 \sqrt{\left.\frac{1}{N} \sum_{j=1}^{N}\left(\hat{y}_{j}-y_{j}\right) / y_{j}\right)^{2}}
$$

where $N$ is the number of observations, $y_{i}$ is the actual data value, and $\hat{y}_{i}$ is the predicted data value. Furthermore, it is the relative changes over the forecast period with which we were most concerned. Given the lagged relationships specified in the demand and supply models and to avoid loss of information at the beginning of the forecast period, the predicted values of the endogenous variables at the end of the ex post period were used with the current projected exogenous input data to conduct the forecast simulations.

\section{Baseline Model Forecast Results}

Given the forecast assumptions, continued reductions in fluid milk demand per capita were expected over the forecast period, but at a reduced rate from reductions realized over the 2002-2005 period (Figure 2). Specifically, from 2002 through 2005, retail fluid milk demand per capita dropped an average of $1.37 \%$ per year whereas (relative to the 2005 baseline level) annualized reductions through 2015 were projected to be $-0.43 \%$ per year (Table 4 ). This was due, in part, to modest growth in the younger-age cohort from 2006 through 2013. After 2013, the proportion of the younger-age cohort in the population was expected to once again begin dropping and contributed to the sharper reductions in demand at the end of the forecast period, combined with continued modest proportional growth by the African American population. Overall, the annualized reductions in per capita demand from 2006 through 2015 are about $32 \%$ of those realized over the last 3 yr. Supplemental sensitivity analysis showed that a stable younger-age cohort at 2005 levels would lessen the annualized reductions in per capita demand by $16 \%$. On a total disappearance basis, factoring in increases in the population, total fluid milk demand was expected to grow at an annualized rate of $0.39 \%$ over the forecast period despite moderate reductions in total fluid milk demand at the end of the forecast period.

Recent growth in retail cheese demand per capita is expected to continue through the forecast period (Figure 3). Furthermore, relative to the actual annual aver- 


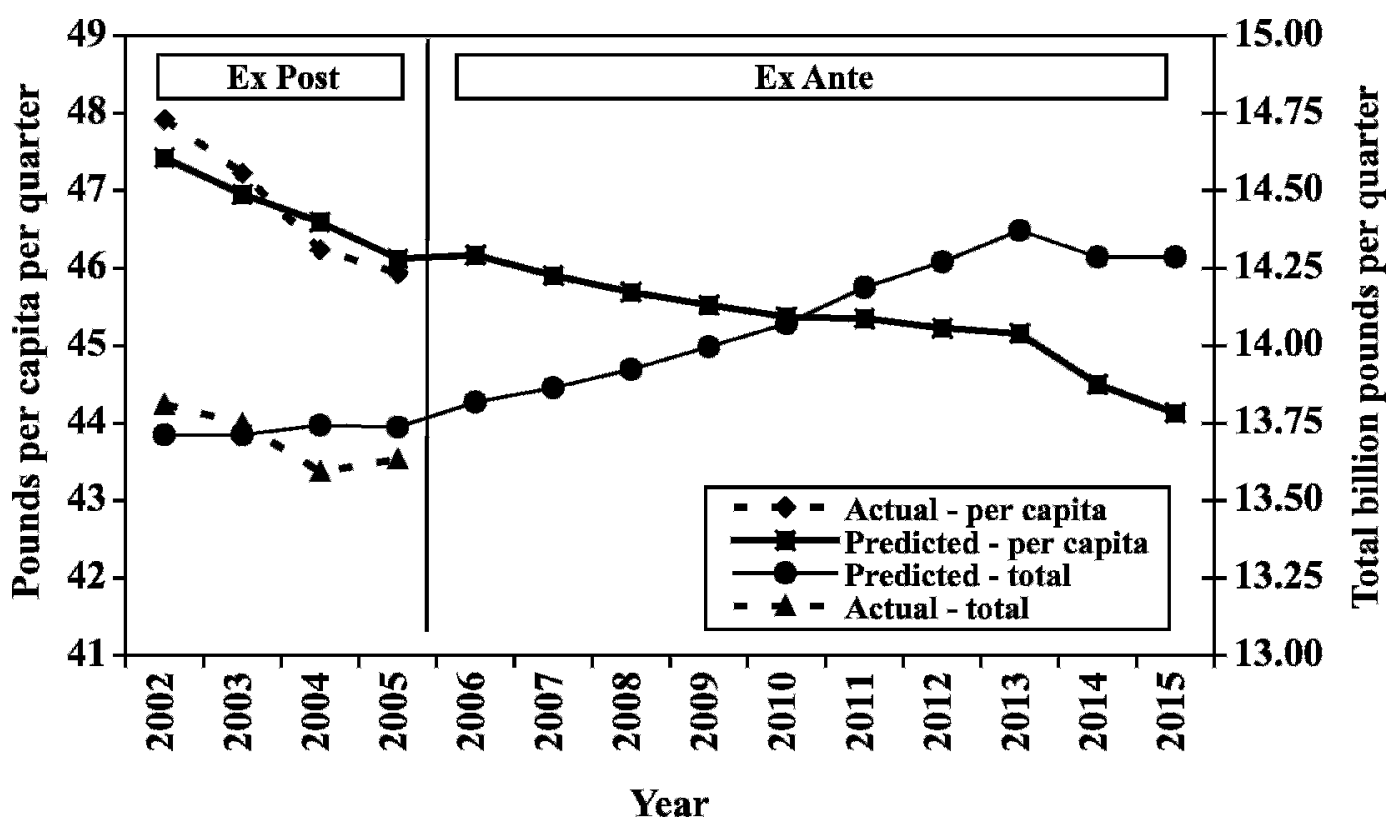

Figure 2. Retail fluid milk demand forecast, total and per capita, 2006-2015.

age rate of growth from 2002 through 2005 (0.47\%), we anticipated that growth in the retail demand for cheese would strengthen over time. We forecasted an average annual growth rate of $0.82 \%$ between 2006 and 2015 (Table 4). The sharper growth in the final 2 yr of the forecast (and, not coincidentally, reductions in fluid milk demand) can be attributed to several factors. First, our assumption of continued growth in spending for food away from home helped to ensure continued growth in demand. Sensitivity analysis on this key variable for cheese demand indicated that without growth in this variable (i.e., assuming fixed food spending away from home at 2005 levels) annualized rates for growth in the demand for cheese were reduced more than $44 \%$ from the baseline simulation and considerably dampened the demand spike in the last 2 yr. In addition, strong contributions were expected from ongoing, strong growth in the size of Hispanic and Asian populations. Assuming fixed population proportions over the forecast period reduced the projected annualized growth rate for cheese demand by more than $15 \%$. On a total disappearance basis, total demand for cheese was expected to grow at an annualized rate of $1.81 \%$ over the forecast period.

For comparing changes in demands for fluid milk and cheese over time, a brief discussion of the structure of the simulation model is worthwhile, particularly given the results estimated for the end of the forecast period. Recall that the farm milk supply can be allocated to several demand uses-fluid milk, cheese, and other manufacturing purposes. Although the demands for fluid milk and cheese (approximately 75\% of total dairy demand) were explicitly modeled relative to changes in various economic and demographic variables, demands

Table 4. Baseline forecast for fluid milk and cheese retail demand, farm milk supply, and farm price

\begin{tabular}{|c|c|c|c|c|c|}
\hline Variable & 2005 & 2010 & 2013 & 2015 & $\begin{array}{l}\text { Annualized } \\
\text { change } \\
(2015), \%^{1}\end{array}$ \\
\hline Retail fluid milk demand per capita ${ }^{2}$ & 46.12 & 45.37 & 45.17 & 44.12 & $-0.43 \%$ \\
\hline Retail cheese demand per capita ${ }^{2}$ & 63.26 & 63.17 & 64.78 & 68.42 & $+0.82 \%$ \\
\hline Farm milk supply ${ }^{2}$ & 44.24 & 44.63 & 46.17 & 47.77 & $+0.79 \%$ \\
\hline Farmer blend price, nominal $(\$ / \mathrm{cwt})^{3}$ & 14.19 & 16.15 & 17.19 & 22.76 & $+6.03 \%$ \\
\hline Farmer blend price index, real $(2002=1)$ & 1.16 & 0.92 & 1.00 & 1.29 & $+1.12 \%$ \\
\hline
\end{tabular}

${ }^{1}$ Annualized changes are relative to 2005 simulation levels.

${ }^{2}$ Demand is in pounds per quarter; supply is in billion pounds per quarter.

${ }^{3} \mathrm{cwt}=$ Hundredweight $=100$ pounds of milk. 


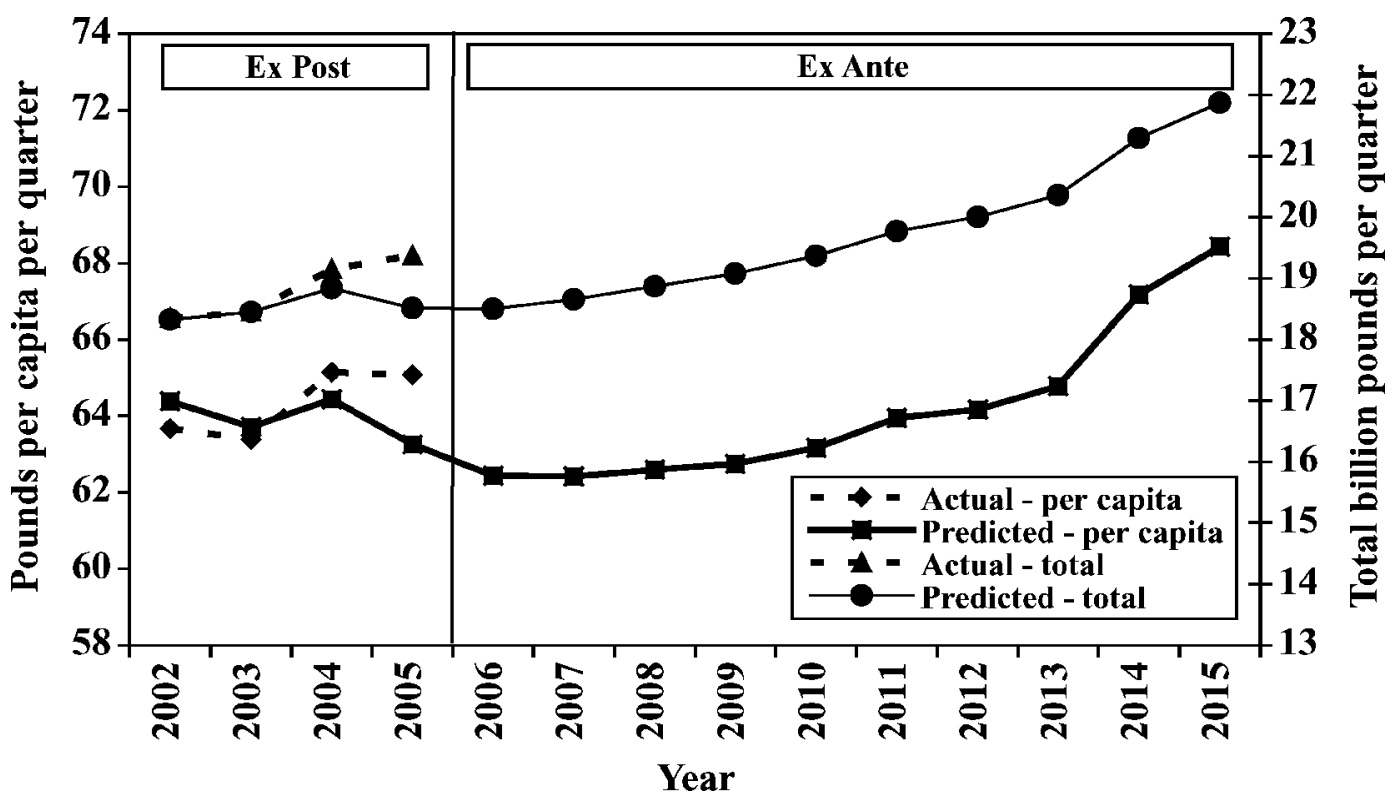

Figure 3. Retail cheese demand forecast, total and per capita, 2006-2015.

for other manufactured products were assumed to be exogenous with forecasted per capita demands held constant at 2005 levels. Constant per capita demands in the exogenous components combined with steady growth in the consuming population implied that an increase in the farm milk supply would be produced to meet this growing total exogenous demand component. In addition, increases or decreases in the demand for either fluid milk or cheese must be compensated by changes in the farm milk supply or relative changes in other endogenous demand components. It is the interaction and adjustment of the endogenous farm milk supply and the demands for fluid milk and cheese, along with respective prices, that "closes" the model and equilibrates all sources and uses of supply. A reduction of one endogenous demand component may be reflected in part in an increase in the other demand component once endogenous farm milk supplies have been calibrated to close the model. In summary, changes in supply and demand are the result of the combination of explicitly modeled endogenous relations of supply and demand, assumed changes in exogenous demand components, and equilibrium closing conditions.

The result of these combined relations in the industry simulation model can best be observed by examining the changes in the farm milk supply (Figure 4). Given that per capita demand for cheese exceeded per capita demand for fluid milk, and assuming constant per capita demand for other manufactured products, we expected the farm milk supply to increase during the next decade. The simulated annualized growth rate in the farm milk supply from 2002 through 2005 was $0.96 \%$ with stronger gains realized in 2005 due to milk prices that were higher in 2004 than in the previous $2 \mathrm{yr}$. In comparison, the average annualized growth rate for the full forecast period (2006-2015) was around 1\%. As anticipated, relatively greater growth in per capita demand for cheese compared with reductions in per capita demand for fluid milk drove this result; that is, the farm milk supply also showed growth on a per capita basis.

Although not shown, retail prices for both products were expected to grow modestly over much of the forecast period (i.e., around $4 \%$ per year); however, the more distinct changes in per capita demands at end of the forecast period resulted in some reductions in retail fluid milk prices and sharper increases in retail cheese prices. Given the changes in per capita demands for fluid milk and cheese over the forecast period, it was clear that a larger and growing proportion of the farm milk supply was being allocated to cheese production. Even though milk designated for nonfluid manufacturing purposes generally garners a lower class price than that designated for beverage purposes, the relatively strong gains in total dairy demand result in increases in the projected average blend price for farmers over the forecast period. Annualized changes in farm milk prices increased, on average, $2.71 \%$ per year through 2013 and rose at a higher annualized rate of $6.03 \%$ through 2015 when the more abrupt economic and demographic changes forecasted for the end of the sample period were considered (Table 4). Note that the model simulation results predicted that the wholesale cheese 


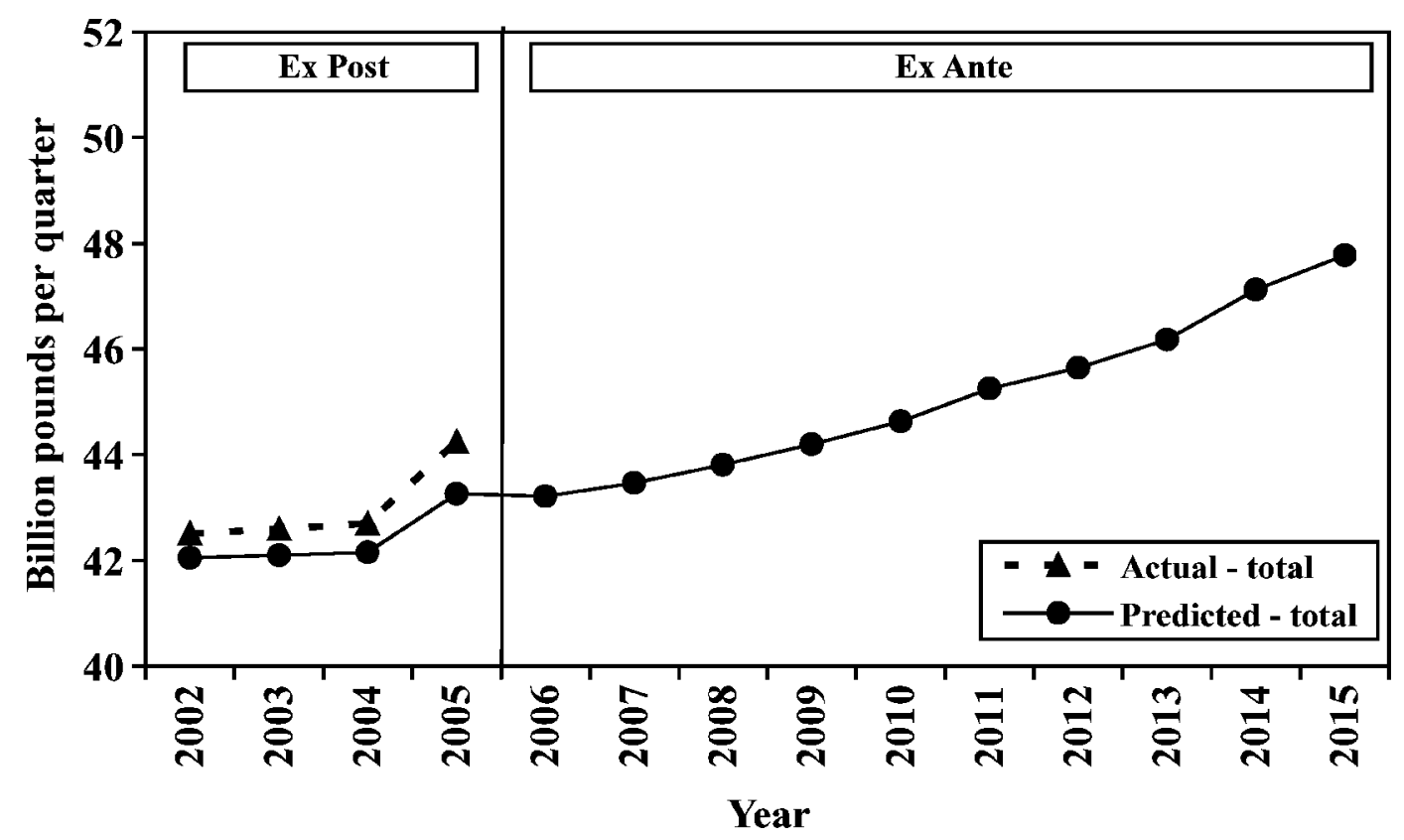

Figure 4. Total farm milk supply forecast, 2006-2015.

price would remain above the assumed government purchase price for cheese implying the competitive market case throughout the forecast period.

Although forecasted increases in nominal farm milk prices were encouraging, profit-maximizing producers determine production based on relative prices-output prices compared with input prices-and it is these relative prices that drive the simulation model. As modeled here, the relative price ratio was determined by the ratio of the farm milk price (endogenous) to the ration price (exogenous). Recall from the preceding discussion that we assumed an average annualized growth rate of $4.4 \%$ for ration costs. Consequently, a computed index of the real farm milk price over time predicted that real prices would be relatively constant and similar to those experienced in 2003 and 2004 (Figure 5). It is only the distinct demand adjustments at the end of the forecast period that signaled an improvement in real farm prices and equated to an average annualized growth rate of $1.12 \%$ for the full forecast period (Table 4 ).

\section{Forecasted Market Impacts from Changes in Generic Advertising}

Additional simulations were conducted to ascertain the impacts of changes in the levels of future spending on generic advertising of fluid milk and cheese on demands for those products and on farm milk prices. Specifically, we evaluated 2 alternative future generic advertising strategies. In the first, we assumed nominal spending on generic advertising of fluid milk and cheese remained constant at the 2005 level. In the second, we assumed that real advertising expenditures increased $10 \%$ from the 2005 level and then remained constant through the forecast period.

Stable Nominal Spending for Generic Advertising. Recall that the baseline simulation was derived under the assumption that real spending for generic advertising in 2005 would be maintained for the next decade. The assumption of constant nominal spending at the 2005 level implied that real spending for advertising would decrease at a rate equivalent to the expected growth in media advertising costs. Based on the 20022005 annual inflation rate in media advertising costs, this implied a real media spending decline of $3.88 \%$ each year.

As shown in Table 5, modest reductions in per capita retail demand and the total farm milk supply resulted from the reduction in real spending for generic advertising. Specifically, average annual per capita demand decreased $0.15 \%$ for fluid milk and $0.22 \%$ for cheese over the forecast period. This reduction in retail demand subsequently implied a decrease in the total farm milk supply of approximately $0.13 \%$.

Given the estimates of inelastic supply and demand schedules, we expected a larger relative change in farm milk prices. Specifically, by maintaining nominal spending for generic advertising over the next decade, average farm milk prices decreased $\$ 0.52 /$ cwt of milk $(2.93 \%)$ relative to the baseline scenario. Relative to 


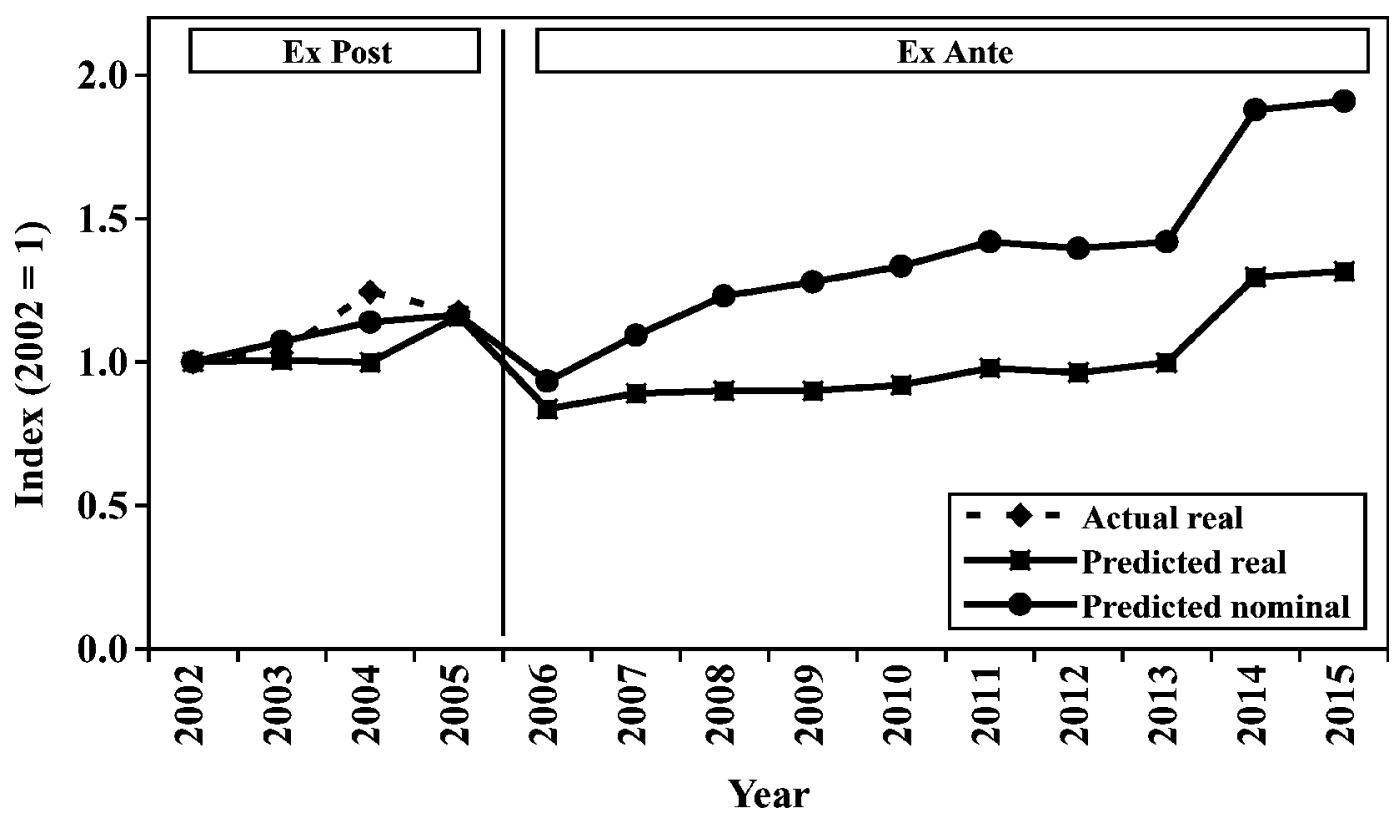

Figure 5. Forecasts for the farm milk blend price index, nominal and real, 2006-2015.

the average baseline farm milk supply, this equated to a reduction in farm-milk producer revenues of approximately $\$ 233$ million per quarter.

Increased Real Spending for Generic Advertising. In the second advertising simulation, we assumed that real spending for generic advertising was increased $10 \%$ from the 2005 level and was fixed for the period 2006-2015. Although the increase in generic advertising did not offset the declining trend in fluid milk demand per capita, it did increase average demand by $0.20 \%$ over the forecast period relative to the baseline simulation (Table 5). This results in an implied fluid milk demand elasticity with respect to generic advertising of 0.020 for the forecast period. The implied elasticity is interpreted as the percentage change in demand for a $1 \%$ change in real generic advertising expenditures.

Retail per capita demand for cheese under this advertising simulation changed little from the baseline simulation-only modest growth of $0.02 \%$ on average. This relatively small change in cheese demand was due predominantly to 2 factors. First, 2005 spending on cheese advertising was only about $23 \%$ of the amount spent for advertising of fluid milk (recall that fluid milk adver-

Table 5. Average demand, supply, and farm-price impacts of alternative generic advertising assumptions, 2006-2015

\begin{tabular}{lllc}
\hline Variable & $\begin{array}{l}\text { Baseline } \\
\text { scenario }\end{array}$ & $\begin{array}{l}\text { Maintain nominal } \\
2005 \text { spending }\end{array}$ & $\begin{array}{c}\text { Increase real } \\
\text { spending } 10 \%{ }^{2}\end{array}$ \\
\hline Retail fluid milk demand per capita $^{3}$ & 45.43 & 45.36 & 45.52 \\
& & $(-0.15 \%)$ & $(+0.20 \%)$ \\
Retail cheese demand per capita $^{3}$ & 63.72 & 63.58 & 63.73 \\
& & $(-0.22 \%)$ & $44.02 \%)$ \\
Farm milk supply & & 44.78 & $(+0.06 \%)$ \\
& 44.84 & $(-0.13 \%)$ & 17.79 \\
Farmer blend price, nominal $(\$ / \mathrm{cwt})^{4}$ & 17.74 & 17.22 & $(+0.28 \%)$ \\
\hline
\end{tabular}

${ }^{1}$ This scenario assumes maintaining nominal per capita spending for generic advertising of fluid milk and cheese at the 2005 level for the entire forecast period. This is equivalent to a real per capita reduction in spending by the advertising media cost inflation rate.

${ }^{2}$ This scenario assumes that the 2005 level of real per capita expenditures on generic advertising maintained in the baseline scenario are increased $10 \%$ for the entire forecast period.

${ }^{3}$ Demand is in pounds per quarter; supply is in billion pounds per quarter.

${ }^{4} \mathrm{cwt}=$ Hundredweight $=100$ pounds of milk. 
tising includes efforts funded by both farmers and fluid milk processors), so the percentage increase in cheese advertising dollars represented a significantly smaller increase in expenditures than the same percentage for fluid milk. Second, the time-varying demand model for cheese from Schmit and Kaiser (2004) shows a negative correlation between the effectiveness of generic cheese advertising and growth in spending on food away from home. Schmit and Kaiser hypothesize that this results from generic cheese advertising that has predominantly promoted at-home consumption. Given that the forecast data assumed steady growth in per capita spending on food eaten away from home, some of the growth in the demand for cheese generated by increased generic advertising spending was offset by a lower marginal rate of response to cheese advertising during the forecast period. As such, the (net) implied cheese demand elasticity with respect to generic cheese advertising over the forecast period was only 0.002 .

More important to dairy producers is the adjustment in total dairy demand (and hence farm milk supply) to the increase in advertising expenditures. The impact of the increase in demands above results in an average quarterly increase of $0.06 \%$ in the total farm milk supply over the forecast period, which equates to an implied elasticity with respect to generic advertising of 0.006 . As illustrated earlier, changes in generic advertising spending affected farm prices relatively more than farm and retail quantities. Specifically, increasing real spending $10 \%$ over the baseline simulation resulted in an average increase in farm prices during the forecast period of $\$ 0.05 / \mathrm{cwt}$ or $0.28 \%$. Equivalently, this implies that, for a $1 \%$ increase in generic advertising, farm milk prices increased $0.028 \%$.

To better illuminate the quantity and price enhancements that derive from an increase in real generic advertising expenditures, we estimated the marginal returns to the increased advertising investment. Specifically, average growth in total producer welfare (roughly, the increase in producer industry revenue from the price and farm-supply enhancements) was expected to be approximately $\$ 22.42$ million per quarter over the forecast period. Comparing this with the assumed change in generic advertising expenditures resulted in a marginal benefit-cost ratio of 5.61:1. In other words, each additional real dollar invested in generic advertising during the forecast period would return $\$ 5.61$ in producer revenue. The implication of such an investment is straightforward: assuming that the economic relationships inherent in the model continue, and given that the marginal benefit-cost ratio exceeds 1.0, increased real expenditures for generic advertising during the forecast period would improve returns to dairy producers relative to the baseline status quo scenario.

\section{CONCLUSIONS}

Changes in population demographics and consumers' food-spending habits have been shown to be the primary forces behind changes in the retail demands for fluid milk and cheese. We examined the dairy industry using econometric models of supply and demand along with projections of market, demographic, and foodspending characteristics to predict the retail demands for these products, the farm milk supply, and farm milk prices for the next decade.

Model simulation results indicated that declines in retail per capita demand for fluid milk will persist but at a reduced rate compared with years past. Specifically, annual reductions in per capita fluid milk demand are expected to be tempered by nearly $32 \%$ relative to reductions that occurred between 2002 and 2005 . The lower rate of reduction is due primarily to a relatively stable proportion of the population $5 \mathrm{yr}$ of age and younger and only moderate growth in the proportion of the population that is African American. On a more optimistic note, the model results indicated that the retail per capita demand for cheese will continue its recent upward trend through the next decade with an average annual growth rate of $0.8 \%$. This appealing result, however, hinges on the implied assumption that real per capita spending on food eaten away from home (a strong cheese-demand determinant) will continue its recent average rate of growth of $1.5 \%$ per year. Constant real per capita spending in this market segment at 2005 levels would reduce increases in cheese consumption by $44 \%$. In addition, the strong rate of growth in cheese consumption was positively affected by projected strong and continuing increases in the proportion of the population that is Asian and Hispanic.

The combined effect of these changes in forecasted demands for fluid milk and cheese at the retail level was reflected in expected changes in the total farm milk supply and in the farm milk price. We anticipate that the annualized growth rate for the total farm milk supply will continue at a rate similar to that realized during the past several years-approximately $1 \%$ per year. Although nominal farm milk prices are expected to increase over the period, real prices (relative to assumed increases in ration costs) would likely be similar to those realized during the past few years and would not increase until the end of the 2006-2015 forecast period.

Supplemental simulations also suggested that net losses in producer revenue would result if only nominal levels of generic advertising spending were maintained in forthcoming years. In fact, by increasing real spend- 
ing for generic advertising relative to the 2005 level (outpacing the media cost inflation rate), returns to the generic advertising investment could be improved. Specifically, for each additional real dollar invested in generic advertising over the forecast period, an additional $\$ 5.61$ in producer revenues would result.

\section{REFERENCES}

Kaiser, H. M. 2005. Why cheese use is up and milk is down. Hoard's Dairyman 150:619.
Liu, D. J., H. M. Kaiser, O. D. Forker, and T. D. Mount. 1990. An economic analysis of the U.S. generic dairy advertising program using an industry model. Northeast. J. Agric. Res. Econ. 19:37-48.

Schmit, T. M. and H. M. Kaiser. 2002. Measuring the impacts of generic fluid milk and cheese advertising: A time-varying parameter application. Res. Bull. No. 2002-06. Dept. Applied Econ. Mgt., Cornell Univ., Ithaca, NY.

Schmit, T. M., and H. M. Kaiser. 2004. Decomposing the variation in generic advertising response over time. Am. J. Agric. Econ. 86:139-153.

US Census Bureau (Population Projections Branch). 2004. U.S. interim projections by age, sex, race, and Hispanic origin. Online: http://www.census.gov/ipc/www/usinterimproj/

USDA. 2006. USDA agricultural baseline projections to 2015. Baseline Rep. OCE-2006-1. February. USDA, Office of the Chief Economist, World Agricultural Outlook Board. Online: http://www.ers.usda.gov/Publications/OCE061 